Teaching \& Learning (2015) 10(1), 45-57

\title{
Changing the Spots of Leopards: A Look into the Process of Teacher Change and its Impact on Inclusive Pedagogy
}

\author{
MONIQUE SOMMA \\ Brock University
}

\begin{abstract}
For the last two decades, systems of education have been shifting special education teaching practice away from segregated classes to inclusive schools (Reiser \& Secretariat, 2012; Sharma, Loreman, \& Forlin, 2012; UNESCO, 1994). Despite much success, this shift has not come without its challenges. Research has found teachers' attitudes and beliefs about students with exceptionalities influence their inclusive pedagogy (Avramidis \& Norwich, 2002; MacFarlane \& Woolfson, 2013; Scruggs \& Mastropieri, 1996). This paper examines the current literature on teacher attitudes and beliefs towards inclusion as well as the process of teacher change. It is concluded that despite unfavourable attitudes, when teachers have training and support paired with authentic experiences, attitudes can shift and inclusive pedagogy adopted.
\end{abstract}

\section{Introduction}

As we examine how teachers' beliefs influence their pedagogy, we can begin to understand how change happens for educators in their practice and move forward, challenging perceptions and breaking down barriers that remain obstacles for creating inclusive learning environments for all students in all schools. Kgothule \& Hay (2013) attest that in order for inclusion to be systematically and competently implemented, the views of school principals and teachers regarding inclusive practices must be established and developed; which is not a simple task. Despite reporting positive views of inclusive education as an idea, educators identified the practical implementation of inclusion to be problematic for their teaching practice (Avramidis \& Norwich, 2002; MacFarlane \& Woolfson, 2013; Scruggs \& Mastropieri, 1996). Although teachers perceived inclusion to have benefits for students with exceptionalities, including the development of independence and socialization skills, Mukhopadhyay (2014) reported that overall teachers had a negative attitude towards inclusion of students with exceptionalities in their classrooms. Based on the aforementioned literature, the present paper examines how one's general positive beliefs about inclusion can be shifted into classroom practice. A review of the current literature on teacher attitudes of inclusion and teacher change will be reviewed, and 
connections that support a framework for the relationship between teacher perception and successful inclusive practice will be discussed.

\section{Background on Inclusive Education}

As a result of the Salamanca Report (1994), systems of education all over the world have been adopting inclusive approaches to education. This framework is based on the premise that neighbourhood schools will accommodate all children despite disability (UNESCO, 1994). UNESCO (1994) describes inclusive education as a way of acknowledging and programming for the diverse needs of all students by allowing for full participation in the education system and in the community. The agreement indicates that in order for successful inclusive practice to occur, curriculum, teaching approaches, and strategies need to change. Inclusive education involves changes in content, approaches, structures and strategies, with a common vision that encompasses the needs of all children (UNESCO, 1994). It is on the premise, as outlined by UNESCO, that many school boards have developed inclusive policies and continue to work towards implementing inclusive practices that meet the needs of all learners by ensuring their participation in the classroom and the school (Reiser \& Secretariat, 2012; Sharma, Loreman, \& Forlin, 2012). Inclusive education can be described as a place where all students are educated in grade appropriate classrooms with their same age peers in their local schools regardless of having an identification of a disability. Students with disabilities go to the same schools as their siblings, have the same learning opportunities, and are engaged in the academic and social activities of the classroom, just as the other children (Bennett, 2009). Porter (2010) further explains that schools that are inclusive support not only the students with disabilities, but also to their teachers in order to accomplish individual goals that are meaningful. Educators and administrators understand inclusion to be about how environments can be created so that all students can be successful, regardless of their ability (Porter, 2010). Giangreco, Cloninger, Dennis \& Edelman, (1994) proposed that inclusive classrooms should demonstrate five characteristics: heterogeneous grouping, a sense of belonging, shared activities with individualized outcomes, use of environments frequented by people without disabilities, and a balanced educational experience. Although there are many visions of what inclusive education should entail, the message is consistent: students of all abilities should have equal opportunities in their classrooms and schools as well as a sense of belonging and success. 
According to Sharma et al. (2012), school boards, administrators and teachers are recognizing that creating truly inclusive schools requires changes in traditional and common practices. In order to accurately comprise the diversity of disability, an inclusive philosophy must be embraced which places the school system accountable when a student is struggling, and not the student. Imbedded practices contrary to this ideal prevent the creation of inclusive classrooms for all students regardless of exceptionality (Bennett, 2009; Sharma et al., 2012).

Many teachers are open and willing to attempt the development of inclusive environments. They question however, what skills are necessary to implement inclusive practices, and how assessment can take place, particularly when only an adequate level of competency is obtained (Sharma et al., 2012). The main barriers to creating inclusive classrooms as identified by teachers include: not having appropriate training in special education, classroom management problems, a disconnect with collaboration between general and special educators and, teachers' perception of a lack of appropriate resources and support to create successful inclusion (Bennett, 2009; Vaughn \& Schrumm, 1995). Classroom teachers recognize that implementing fully inclusive practices impact their role in the classroom. In order to address the diversity of abilities in the classroom teachers must adjust teaching styles including how they program for, plan and execute curriculum (Forlin, 2001; Reiser and Secretariat, 2012). Most research on implementing inclusive practices indicates that in order for teachers to be effective and ensure each student is successful, ongoing professional development and support from administration and experts in the field is required (Bennett, 2009; Forlin, 2001; Porter, 2010; Vaughn \& Schrumm, 1995).

\section{Teacher Attitudes Regarding Inclusion}

As the number of students with exceptionalities attending local schools continues to increase - due to integrated and inclusive ministry and school policies — classrooms will become increasingly diverse, challenging educators to re-evaluate their perceptions and ideals and adjust their pedagogy (Berry, 2011; Mukhopadhyay, 2014). A significant body of research indicates that globally, teachers' positive attitudes towards the inclusion of students with exceptionalities are critical to successfully create an inclusive classroom. Given that school board and ministry policy regarding the inclusion of students with exceptionalities mandates inclusive practice to be 
implemented in the classroom, attitudes about students with exceptionalities is particularly relevant especially when teacher attitudes are negative (Male, 2011).

In order for educators to successfully meet the diverse needs of their students, literature supports educators requiring adequate knowledge, thorough training and skills, as well as favourable attitudes towards inclusive education (Berry, 2011; Ivey \& Reinke, 2002; Male, 2011). Teachers' attitudes and willingness to include students with diverse abilities combined with their perceived confidence or sense of efficacy in being able to work with these students, are factors in determining the success of inclusion (Friend \& Bursuck, 2009; Richardson, 1998). In similar studies on teacher efficacy, teachers indicated that they were more confident and could successfully teach while including students with exceptionalities in their classes once they obtained knowledge and skills (Leyser, Zeiger, \& Romi, 2011).

A literature review about teacher attitude regarding inclusion of students with exceptionalities found that overall teachers possessed a neutral or negative attitude toward inclusion of students with exceptionalities in their classrooms (Boer, de, Pijl, \& Minnaert, 2011). In 26 studies examined, most teachers did not rate themselves as competent to teach students with exceptionalities. Boer et al. (2011) also cited several studies that showed teachers with one to five years of teaching experience held significantly more positive attitudes towards the inclusion of students with special needs when compared with teachers who possessed six or more years of experience. In comparison to years of experience teaching, Boer et al. (2011) reported that teachers who had experience and training with students with exceptionalities held more positive attitudes compared to those colleagues who did not have training or experience. Positive attitude declining as years of teaching experience increases has also been supported in other literature (Alghazo \& Naggar Gaad, 2004; Glaubman \& Lifshitz , 2001). Mukhopadhyay’s (2014) framework for stages of professional development for educators categorizes educators based on their beliefs about professional development and changing practice. Teachers who were at the stages of professional development of either Competency Building or of Enthusiasm and Growth (beginning half of their careers) were more willing to engage in pedagogical change when compared to those in the last half of their career, especially in the years before retirement (Boer et al., 2011; Mukhopadhyay, 2014). Teachers have also identified that specific training was a critical prerequisite to effectively implement inclusion in their classrooms (Mukhopadhyay, 2014; Leyser, et al., 2011). As in other studies, teachers expressed feeling 
unequipped with the knowledge and teaching experience necessary in order to decide whether they could effectively implement inclusion (Male, 2011; Kgothule \& Hay, 2013). MacFarlane \& Woolfson (2013) found similar results; however, they concluded that teachers with only more training held more positive views of inclusion whereas teachers with more experience were less likely to hold positive views on including children with exceptionalities. These findings allude to the importance of the appropriate training including opportunities for authentic experiences in order to help teachers facilitate inclusive classrooms.

Jordan et al. (2010) examined the relationship between elementary general education teachers' beliefs about disability, their roles in inclusive classrooms, and how these variables were related to teaching practices. Their findings indicated that $25 \%$ of the teachers interviewed held 'pathognomonic' beliefs, "disability is an internal, fixed, and pathological condition of the individual that is not amenable to instruction" (p. 262). Teachers who held these beliefs, focused on the label of the disability as the explanation for the student's underachievement, and thus believed that students with disabilities were the source of their own learning difficulties. On the other hand, teachers with 'interventionist' beliefs viewed disability as 'created in part by a society that is designed for the able, and that creates barriers for those who have disabilities" ( $p$. 262). Jordan et al. (2010) found that only $20 \%$ of the teachers held interventionist beliefs and also viewed creating access to learning opportunities by use of accommodations and work as their responsibility.

Independent of the terms used to describe teacher beliefs, teachers' general perceptions about disabilities (whether positive or negative) influenced their attitudes about including students with disabilities in regular classrooms. Although there are structural factors including training and support, which can influence teacher ability to implement inclusion; attitudes and beliefs of disability and inclusion were the most confounding factors in the aforementioned literature. The more positive attitudes held by newer teachers are indicative of their lived experiences regarding students with disabilities in classrooms. These teachers are in a position where they have lived through the beginning stages of the inclusion movement (as a result of the Salamanca Report, 1994) as students themselves. Newer and younger teachers do not have the same experience with special education as a student or as a teacher themselves who has an understanding of special education pre-inclusion and pre- Bill 82 (in 1980, Bill 82 was passed to make school boards in Ontario accountable for the education of students with disabilities). As 
our experiences both as students and educators shape our beliefs and attitudes over time, the process of how a change in attitudes and beliefs are deeply connected to pedagogy is examined further.

\section{Teacher Change Process}

The process of change as experienced by educators is a phenomenon in which researchers have attempted to understand in order to program for professional development (Richardson, 2008; Maskit, 2011). In a long-term collaborative study of teacher change, (Richardson, 1994) found that when a teacher tries new activities, s/he informally evaluates the activities based on several factors to determine effectiveness, including but not limited to whether activities fit within his/her set of beliefs about teaching and learning, and whether the activities engage the students while maintaining his/her desired degree classroom control. It was concluded that if the teacher felt the activity did not work based on the previous criteria, it would be quickly abandoned or changed completely (Richardson, 1994). Recently, Maskit (2011) furthered this finding and found educators responded to implementing change in different ways depending on the stage of their career. Teachers in the beginning and middle stages of their careers viewed change more positively, whereas, teachers at the end of their careers viewed change more negatively (Maskit, 2011). Along with positive attitude toward change, teachers at the beginning of their careers were more actively involved in the number of attempts to implement changes in the classroom and may see the implementation of change as an inseparable part of their profession (Maskit, 2011).

In further examining how one undergoes a change in perception, Pyhältö, Pietarinen, \& Soini, (2012) explained the interrelatedness in the way educators perceived a change and their place within the change. Teachers often resisted change mandated or suggested by others, yet; research shows that teachers participated in voluntary change- which was self-initiated or selfdirected (Richardson, 1998). Richardson (1998) believes teacher change is most successful when it is executed in a way that promotes teacher involvement in the process, and encourages coherence among teachers within the school or district. In explaining the sensitive nature of teacher change process, Richardson (1998) refers to Morimoto's (1973) view on change process; "When change is advocated or demanded by another person, we feel threatened, defensive, and perhaps rushed. We are then without the freedom and the time to understand and to affirm the 
new learning as something desirable, and as something of our own choosing. Pressure to change, without an opportunity for exploration and choice, seldom results in experiences of joy and excitement in learning" (p. 255). Pyhältö et al. (2012) found that those who perceived themselves as active change agents possessed a holistic and functional perception of the change. Despite that educators can and do identify change opportunities, the challenge for change remains that there is a lack of shared and informed assumptions about how change happens (Kgothule, \& Hay, 2013; Pyhältö et al., 2012). Jordan et al., (2010), also found that the overall school environment had a significant influence on teachers' beliefs and their views about their own roles and responsibilities within the school structure.

Literature on teacher change and school change consistently indicates the essential support of school administration in creating a culture that embodies the change (Miles, 1998; MacFarlane \& Woolfson, 2013). Similarly, Jordan et al., (2010) found that teachers' beliefs were highly influenced by the culture and ethos of the school. The authors concluded that when interpreting beliefs, researchers need to understand the beliefs as socially contextualized by the views of the school as a whole, rather than from a personal viewpoint (Jordan et al., 2010). Mukhopadhyay (2014) reports that teachers who have had training and direct experience with students with exceptionalities seem to be the most accepting and thus the most inclusive teachers, even when they have less teaching experience. It is important to consider from a school culture perspective that this is the teacher likely to have the least influence within the school in regards to change. Gibbs (2007) proposes that in order to effect change in teacher beliefs about inclusion, there needs to be an interaction between teacher perception of personal self-efficacy and the overall efficacy within the school building.

Evans (1996) describes a teacher's readiness for change to occur when the teacher can balance autonomy with community. The ideal is a community of practice (the school) where teachers engage with each other in critical discussions regarding pedagogy and practice and encourage one another to be inquirers in this setting. Schools as communities of practice require many levels beyond teachers engaging in critical discussions. Administrators and school boards are factors that can support this process by providing opportunities for teachers to engage in discussions and reflections. Evans (1996) described the hierarchal structure of schools and school systems as the main challenge faced by schools or boards facilitating change where teachers are supported to develop their autonomy and fosters a community of learners. The 
challenge of having all levels 'buy in' is crucial in fostering this learning community and thus cannot be a top down or bottom up process: all members must be have ownership over the change process.

\section{Changing Attitudes}

Many constructed beliefs about disability and special education are rooted in historical understandings of disability. Changing educators attitudes and beliefs with regard to inclusion and disability can be a challenge; and even more so when the attitudes and beliefs have been embedded in one's belief system for most of his/her life. Teachers are often not aware of the assumptions, theories or educational beliefs they hold (Carrington, 1999). According to Carrington (1999), a teacher may adopt components of a stance that seem 'right' to them at some point in their career perhaps because they match the expectation of others, such as colleagues who they admire or with whom they affiliate. Within this understanding of belief development, a teacher's educational platform exists at two levels: that which they say they believe and intend (their espoused theory) and those assumptions, beliefs and intents one can infer from their behaviour (their theory in use) (Carrington, 1999). This implies a conflict may exist at any given time where a teacher's beliefs do not align with how his/her behaviour is perceived by others. Carrington (1999) concludes that it is not until one's espoused theory of action matches one's theory in use that one's beliefs can be considered in alignment.

Research also suggests that in order to challenge and change their beliefs, teachers need the opportunity to actively engage and experience success in using inclusive practices in their classrooms and only then will they experience a positive change in attitude and perception about inclusion (Evans, 1996). Richardson (1998) discussed a view described by Gallagher, Goudvis, and Pearson (1988) termed "mutual adaptation," where teachers systematically and thoughtfully approached their own change process. It was suggested that mutual adaptation might be the best methodology when attempting to evoke dramatic change (such as shifts in orientations and beliefs) regarding inclusion of students with exceptionalities (Richardson, 1998). This being said, it is also important for educators to be given opportunities to engage in a change process and may benefit from guidance as they work through questions that arise from their personal reflection. 


\section{The Impact of Teacher Change on Inclusion}

Connections can be made between teacher attitudes about students with exceptionalities and teacher change and this can be applied to teacher perceptions regarding including student with exceptionalities in classrooms. According to Richardson (1998), it is necessary for teachers to create a sense of autonomy that goes beyond their classroom for the students they teach. When teachers and schools think globally about inclusion, they have a better understanding of how their efforts to create an inclusive classroom impacts the overall inclusion of students within the school, the program, and the community (Richardson, 1998). In order to do this, the responsibility cannot solely be that of the teachers. Schools and school systems need to also be accountable for this change process by fostering change with the attitudes in which the school and school system impose (Richardson, 1998).

In Male's (2011) study of teachers enrolled in a Master's programme in Special and Inclusive Education, there was an overall attitudinal shift for four of six categories of inclusion. These findings suggested that the educators possessed more positive attitudes at the end of the course, compared to the beginning of the course. For this group of teachers, the process of change that occurred by being enrolled in this professional development course was a positive shift in attitude related to inclusion of students with exceptionalities (Male, 2011). Teacher reports in this particular study indicated that assumptions and beliefs about inclusion were challenged, and as a result, their pedagogy and practice altered. Leyser et al. (2011) similarly found a significant effect when examining the intensity of exceptionality training the teachers engaged in, and the teachers' self-efficacy with respect to being able to implement successful inclusive practices in their classrooms. Teachers developed a change orientation that led them to reflect continually on their teaching and classrooms, and experiment thoughtfully with new practices. Through the development of their autonomy, the teachers in these studies became more confident in their decision-making ability, felt empowered, and took responsibility for implementing inclusive practice in their own classrooms (Richardson, 1998). Similar studies found that in order for teachers to have a true change in beliefs and perceptions, it is necessary for them to have direct high quality interactions with students who have exceptionalities (Forlin, Loreman, Sharma and Earle, 2009; Sharma et al., 2012). Finally, in order to challenge personal assumptions about individuals with disabilities, student teachers (and classroom teachers) needed 
to be provided with the time and opportunity to develop relationships with individuals with disabilities (Forlin, et al., 2009; Sharma, et al., 2012).

\section{Conclusion}

This paper set out to examine the influence of teacher change process on attitudes and perceptions of students with exceptionalities and on teacher's ability to implement inclusive education. Although findings regarding teacher attitudes toward including students with exceptionalities in their classrooms are mixed, the data supports that teacher change and positive attitudes can take place through appropriate professional development. Through this analysis, we can better understand some of the processes that challenge teachers to implement inclusive education. Beliefs and perceptions fuel our pedagogy and practice. When school systems and administration provide teachers with opportunities to reflect on their practice and challenge their beliefs, the outcome can be changes in not only behaviour but also in rational that accompanies new inclusive practice (Evans, 1996; Pyhältö et al., 2012; Richardson, 1998). The findings presented set the stage for future movement in teacher training and implementation of inclusive practice. Through authentic experience and opportunities for learning, teachers can, and do, change their perceptions. Once teachers have challenged their beliefs and find clarity in their outlook on what inclusion is, they need to be provided with practical knowledge and exposure to students with exceptionalities in order to carry out this new understanding. Jordan, Schwartz, \& McGhie-Richmond (2009) suggested that there are two specific mindsets involved in a change of perception. Firstly, teachers who viewed diversity as normal and perceived that all children can learn tend to be more effective in teaching inclusive classrooms. These teachers disregarded a charity based model where children with special needs were in need of 'fixing', rather, focused on the idea that all children can learn and work to assist students with exceptionalities and develop fully. Secondly, effective teachers accepted that it was their job to teach all children and took ownership to break down barriers using differentiating instruction for all students in their class (Jordan, Schwartz, \& McGhie-Richmond, 2009). When educators engaged in reflective professional learning related to inclusive education, they had the opportunity to create dynamic inclusive classrooms that met the needs of all learners. When a school environment is created to support teachers to engage in reflective professional learning and create inclusive classrooms, we will have a school that meet the needs of all the learners it serves. 
Tips for educators planning for inclusive classrooms:

- Recognize that change takes time. Choose one area of your practice as a starting point: classroom set-up or one subject area are good places to start.

- Consider your personal bias as an educator. What beliefs do you currently hold? How has your personal and professional life contributed to your beliefs? How do your beliefs influence your practice?

- Have conversations with colleagues about their inclusive practice. Ask what strategies they use? How do they evaluate success? Where do they access support? Observe their work.

- Select professional development (workshops or reading) which supports your personal growth towards inclusive practice. Find someone to talk about your learning with.

- Reflect on your challenges and progress. Journal or document your work for your own reflection and personal growth.

- Be flexible and brave. Try something in a lesson that makes you feel a little bit uncomfortable; but, supports your lesson to be more inclusive. You might be surprised by the outcome.

\section{References}

Alghazo, E., Gaad, N., \& El, E. (2004). General education teachers in the United Arab Emirates and their acceptance of the inclusion of students with disabilities. British Journal of Special Education, 31 (2), 94-99. doi:10.1111/j.0952-3383.2004.00335

Bennett, S. (2009). What works? Research into Practice. Exceptionality, 10(12), 18-22.

Berry, R. (2011). Voices of experience: general education teachers on teaching students with disabilities. International Journal of Inclusive Education, 15(6), 627-648. doi:10.1080/13603110903278035

Boer, A. de, Pijl, S., \& Minnaert, A. (2011). Regular primary schoolteachers' attitudes towards inclusive education: a review of the literature. International Journal of Inclusive Education, 15(3), 331-353. doi:10.1080/13603110903030089

Carrington, S. (1999). Inclusion needs a different school culture. International Journal of Inclusive Education, 3(3), 257-268.

Evans, L. (1997). Understanding teacher morale and job satisfaction. Teaching and TeacherEducation, 13(8), 831-845.

Forlin, C. (2001). Inclusion: Identifying potential stressors for regular class teachers. Educational Research, 43(3), 235-245.

Forlin, C., \& Loreman, T. (2009). Demographic differences in changing pre-service teachers' attitudes, sentiments and concerns about inclusive education. International Journal of Inclusive Education, 13(2), 195-209. doi:10.1080/13603110701365356

Friend, M., \& Bursuck, W. (2002). Including students with special needs: A practical guide for classroom teachers. Boston : Allyn and Bacon. 
Giangreco, M. F., Cloninger, C. J., Dennis, R. E., \& Edelman, S. W. (1994). Problem-solving methods to facilitate inclusive education. Creativity and Collaborative Learning: A Practical Guide to Empowering Students and Teachers, 321-346.

Gibbs, S. (2007). Teachers' perceptions of efficacy: beliefs that support inclusion or segregation. Educational and Child Psychology, 24(3), 47-53.

Ivey, J., \& Reinke, K. (2002). Pre-service Teachers' Attitudes towards Inclusion in a Nontraditional Classroom. Electronic Journal of Inclusive Education 1(6), article 4. Retrieved from http://corescholar.libraries.wright.edu/ejie/voll/iss6/4/

Jordan, A., Glenn, C., \& McGhie-Richmond, D. (2010). Effective Teaching (SET) project: The relationship of inclusive teaching practices to teachers' beliefs about disability and ability, and about their roles as teachers. Teaching and Teacher Education 26(2), 259266.

Jordan, A., Schwartz, E., \& McGhie-Richmond, D. (2009). Preparing teachers for inclusive classrooms. Teaching and Teacher Education 25(4), 535-542.

Kgothule, R., \& Hay, J. (2013). Educators' Views on Management Practices in the Implementation of Inclusive Education: An Ecosystemic Approach. Journal of Human Ecology 42(1), 33-41.

Leyser, Y., Zeiger, T., \& Romi, S. (2011). Changes in self-efficacy of prospective special and general education teachers: Implication for inclusive education. International Journal of Disability, Development and Education 58(3), 241-25. doi:10.1080/1034912X.2011.598397

MacFarlane, K., \& Woolfson, L. (2013). Teacher attitudes and behavior toward the inclusion of children with social, emotional and behavioral difficulties in mainstream schools: An application of the theory of. Teaching and Teacher Education 29, 46-52. doi: 10.1016/j.tate.2012.08.006

Male, D. (2011). The impact of a professional development programme on teachers' attitudes towards inclusion. Support for Learning 26(4), 182-186. doi/10.1111/j.14679604.2011.01500.x/full

Maskit, D. (2011). Teachers' attitudes toward pedagogical changes during various stages of professional development. Teaching and Teacher Education 27(5), 811-968. doi: 10.1016/j.tate.2011.01.009

Miles, M. (1998). Finding keys to school change: a 40-year odyssey. International handbook of educational change 26(4), 182-186

Mukhopadhyay, S. (2014). Botswana primary schools teachers' perception of inclusion of learners with special educational needs. Journal of Research in Special Educational Needs 14(1), 33-43. doi/10.1111/j.1471-3802.2012.01269.x/full

Porter, G. L. (2010). MAKING CANADIAN SCHOOLS INCLUSIVE : A CALL TO ACTION. Education Canada, 44(1), 62-66. 
Pyhältö, K., Pietarinen, J., \& Soini, T. (2012). Do comprehensive school teachers perceive themselves as active professional agents in school reforms? Journal of Educational Change 13(1), 95-116

Reiser, R., \& Secretariat, C. (2012). Implementing inclusive education: a commonwealth guide to implementing article 24 of the UN convention on the rights of persons with disabilities. Commonwealth Secretariat London. Retrieved from http://www.worldofinclusion.com/res/internat/Commonwealth Guide.doc

Richardson, V. (ed.). (1994). Teacher Change and the Staff Development Process: A Case in Reading Instruction. New York: Teachers College Press.

Richardson, V. (1998). How teachers change. Focus on Basics. Retrieved from http://www.ncsall.net/index.php?id=395

Sharma, U., Loreman, T., \& Forlin, C. (2012). Measuring teacher efficacy to implement inclusive practices. Journal of Research in Special Educational Needs, 12(1), 12-21.

UNESCO (1994). Final Report, World Conference on Special Needs Education: Access and Quality. Paris. Retrieved from http://unesdoc.unesco.org/images/0009/000984/098427eo.pdfSalamanca

Vaughn, S., \& Schumm, J. S. (1995). Responsible inclusion for students with learning disabilities. Journal of Learning Disabilities, 28(5), 264-270.

doi:10.1177/002221949502800502 